\title{
IN COMMEMORATION OF PUBLICATION
}

In order to keep abreast with the modern progress in the Dental Science, both in the basic and applied fields, we have been devoting our concerted attentions to the enhancement of our school facilities as well as their standards and two years have elapsed since the Graduate Course was successfully founded in our college.

For some time past, we have been cherishing an earnest desire to publish an academic journal in English so that we may make public the results of our rising and veteran research workers engaged in the realm of the Dental Science. In introducing this first attempt of ours before the public in spite of difficulties involved, we cannot help expressing a sense of great delight. Being a quarterly publication, this journal brings the results of our latest researches to the interested public concerned. If this little attempt will contribute towards the betterment of world relationship in the future through the exchange of mutual opinions and researches, we shall be more than rewarded for our efforts.

In conclusion, it should be added that any inquiry or criticism regarding the papers appearing in the journal will be gratefully received.

Very respectfully yours,

\section{Masaru SUZUKI}

Dean, College of Dentistry, Nihon University,

Surugadai, Tokyo, Japan 